\title{
Long-Term Effects of Untreated Adolescent Idiopathic Scoliosis: A Review of the Literature
}

\author{
Hans-Rudolf Weiss ${ }^{1}$, Nikos Karavidas ${ }^{2}$, Marc Moramarco ${ }^{3}$, Kathryn Moramarco ${ }^{3}$ \\ ${ }^{1}$ Gesundheitsforum Nahetal, Gensingen, Germany \\ ${ }^{2}$ Scoliosis Best Practice Rehab Services, Athens-Thessaloniki, Greece \\ ${ }^{3}$ Scoliosis 3DC, 3 Baldwin Green Common, Woburn, MA, USA
}

\begin{abstract}
Currently, adolescent idiopathic scoliosis (AIS) is principally regarded as benign, but some researchers have cited serious or extreme effects, including severe pain, cardiopulmonary compromise, social isolation, and even early death. Therefore, exploration of the long-term effects of AIS, the most common type of idiopathic scoliosis, is warranted. The purpose of this review was to examine the long-term studies on the natural history of AIS and/or reviews concerning the long-term effects of untreated AIS. A PubMed search was conducted using the key words idiopathic scoliosis, long-term effects and idiopathic scoliosis, natural history. For further analysis, references cited in those studies were reviewed for additional, related evidence not retrieved in the initial PubMed search. A review of the pertinent bibliography showed that older natural history studies did not distinguish between late-onset scoliosis (referred to in this paper as AIS) and early-onset scoliosis (EOS). The more recent studies offer such important distinction and reach to the general conclusion that untreated AIS does not lead to severe consequences with respect to signs and symptoms of scoliosis. It is possible that earlier studies may have included patient populations with EOS, leading to the perception of untreated scoliosis as having an unusually high morbidity rate. Studies on the long-term effects of AIS that specifically excluded EOS patients conclude that AIS is a benign disorder. This indicates that for research and reporting purposes, it is important to distinguishing between AIS and EOS. This will allow the practitioner and patient and their families to decide on an optimal treatment plan based on the most appropriate prognosis.
\end{abstract}

Keywords: Scoliosis; Long-term adverse effects; Treatment

\section{Introduction}

Scoliosis is a three-dimensional deformity of the spine and trunk; it includes lateral deviation, rotation, and a disturbed sagittal profile [1-4]. Treatment is indicated because scoliosis may lead to reduced quality of life and diverse health issues in some patients $[1,5,6]$.

Scoliosis may be caused by disturbances of the neuromuscular system (neuromuscular scoliosis), alterations of soft tissue (e.g., Marfan's syndrome and Ehlers-Danlos syndrome), alterations of the nervous system (neurofibromatosis), failure of formation/segmentation of vertebrae and ribs (congenital scoliosis), and other causes [7]. The majority of patients with scoliosis have idiopathic scoliosis $[8,9]$.

Adolescent idiopathic scoliosis (AIS) is the most common form of scoliosis ( $80 \%-90 \%$ of the scoliosis population) [10]. AIS is also sometimes referred to as "late-onset

\footnotetext{
Received Apr 15, 2016; Revised May 17, 2016; Accepted May 18, 2016
}

Corresponding author: Hans-Rudolf Weiss

Gesundheitsforum Nahetal, Alzeyer Str. 23, D-55457 Gensingen, Germany

Tel: +49-6727-894040, Fax: +49-6727-8940429, E-mail: hr.weiss@skoliose-dr-weiss.com 
scoliosis" when it occurs at the age of 10 or later in adolescence [10]. In contrast, early-onset idiopathic scoliosis (EOS) has a far lower prevalence $(11 \%-15 \%$ of all idiopathic scoliosis cases) [10]. EOS can be subdivided into two groups: infantile idiopathic scoliosis, which develops before the age of 3, and juvenile idiopathic scoliosis, which has its onset after the fourth year of life [10]. The deformities may increase during phases of rapid growth [2].

Studies have described the natural history of the disorder during growth $[2,4,9,11-14]$. They indicate that age, gender, curve size (Cobb angle), menarcheal status, and Risser sign are the most critical factors for predicting curve progression during growth. According to Lonstein and Carlson, the risk of progression can be calculated for curves between $20^{\circ}$ and $29^{\circ}$ [11]. This calculation is the basis for the current indication guidelines $[15,16]$.

The purpose of this review was to identify and evaluate long-term studies on the natural history of AIS or reviews covering the long-term effects of untreated AIS. Most recent studies on the long-term natural history of scoliosis consider AIS as being benign in principle [1,5,17-19]. However, some practitioners continue to report severe pain, cardiopulmonary compromise, lack of social participation, and early death as negative consequences of AIS [20]; these citations are based on a paper that includes a patient population sample treated between 1911 and 1919 [21].

Occasionally, these long-term indications are used as a basis for the recommendation of surgical intervention [20]. This is applicable to AIS patients with curve magnitudes of $\geq 40^{\circ}$ with a potential for further growth and for those with curve magnitudes of $\geq 50^{\circ}$ at or near skeletal maturity. This is standard practice, although there is a clear absence of high-level evidence for recommendation of spinal fusion surgery [22-26]. Therefore, the indications for surgery need to be reevaluated based on the natural long-term effects of patients with AIS (the most prevalent population).

\section{Materials and Methods}

A PubMed search was conducted on October 28, 2015 using the following keywords: (1) idiopathic scoliosis, longterm follow up, natural history; and (2) idiopathic scoliosis, natural history

In addition, the literature referenced in the reviews retrieved during the search was examined to uncover additional studies not displayed in the results of the PubMed search.

\section{Results}

The initial search returned fourteen citations, of which four appeared to satisfy our review scope [27-30]. The second search resulted in 174 citations, of which twenty-six were considered relevant to our purposes $[2,9,13,14,18,27$ 47]. Seven reviews addressing the long-term consequences of AIS $[1,4,9,12-14,18]$ were also identified (Table 1). Four studies included data on long-term effects with a followup time of 20 years or more $[5,17,19,21]$.

One early study by Nilsonne and Lundgren [21] was a retrospective chart review. The authors concluded that idiopathic scoliosis may lead to severe pain, cardiopulmonary compromise, lack of social participation, and early death; however, their report did not specify age at diagnosis, and at least ten patients were juveniles at the time of admission into the study.

For scoliosis, an accurate age of onset is not always easily determined. A study from 1978 concluded that scoliosis screening is not necessary before the ages of 12 [45]; this recommendation clearly prevents determining the true age of onset.

The Iowa studies $[5,17,19]$ defined AIS as idiopathic scoliosis that begins between the ages of 10-14 and concluded that AIS does not lead to significant health problems other than non-disabling back pain and cosmetic concerns. We found only few studies related to the longterm consequences of untreated AIS (Table 2) with a follow-up period exceeding 20 years $[5,17,19]$, one of which

Table 1. Search 1 (idiopathic scoliosis, long-term follow up, natural history) revealed 4 papers on long-term results of untreated patients, search 2 revealed 11 papers on long-term results of untreated patients

\begin{tabular}{lcc} 
& All papers & Long-term results \\
Search 1 & 14 & 4 \\
Search 2 & 174 & 11 \\
\hline
\end{tabular}


Table 2. Long-term studies on untreated patients with idiopathic scoliosis with a follow-up of 20 years or more

\begin{tabular}{lcc} 
Study, year & Benign & Fatal \\
Nilsonne and Lundgren [21], 1968 & - & + \\
Collis and Ponseti [17]"), 1969 & + & - \\
Weinstein et al. [19] $]^{a}, 1981$ & + & - \\
Weinstein et al. [5] $]^{\text {l) }}, 2003$ & + & - \\
\hline
\end{tabular}

alUntreated patients from the lowa series had a benign course, while Nilsonne and Lundgren (1968) [21] have described a fatal course of idiopathic scoliosis.

had a 50-year follow-up [5].

As a result of this review, we can conclude that AIS, when left untreated, does not lead to severe long-term health consequences $[1,5,13,17-19,30,48]$.

\section{Discussion}

We determined that studies that include the most specific definition of AIS indicate that AIS, when left untreated, does not have severe long-term consequences $[1,5,13,17$ $19,30,48]$. This is in contrast to some early 20th century studies on idiopathic scoliosis, which included patient samples from as early as the 1920s [21,45], that did not differentiate idiopathic EOS from AIS in the sample population. One such study in particular, which concluded that untreated idiopathic scoliosis can have fatal consequences, included patients with EOS [21].

This conclusion is not necessarily valid for patients with AIS. It is now known that age at diagnosis is an important factor and must be taken into consideration because the earlier the onset, the more serious the prognosis $[1,49]$. This lack of distinction between EOS and AIS could be one significant reason for the disparity between conclusions of older [21] and more recent studies [1,5,13,17$19,30,48]$.

It should also be acknowledged that at the beginning of the 20th century, people rarely showed themselves uncovered publicly. At that time, clothing did not readily reveal the shape of the body, nor did the people wear swimwear with exposed back and torso, thus offering less opportunity for earlier detection. For this reason, it is possible that scoliosis may not have been detected as commonly and as early as it is nowadays.

During that time period (20th century), in Germany, it was also common for patients seeking scoliosis treatment to exhibit curves already exceeding $90^{\circ}$ (Fig. 1) $[6,50]$. School screening programs implemented in the late 20th

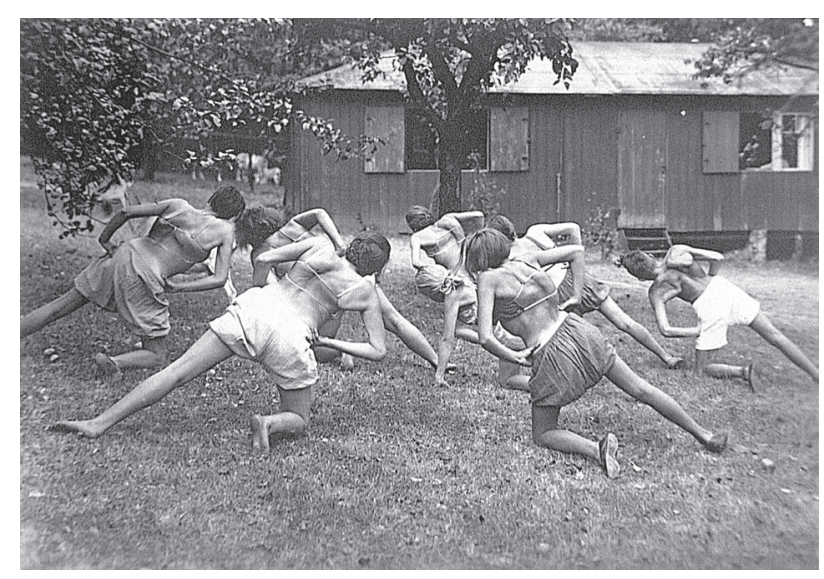

Fig. 1. Patients treated at the Katharina Schroth institute in the 1920s. Most patients presented with curvatures (Cobb angles) exceeding $90^{\circ}$ [6].

century improved scoliosis detection. Earlier detection may now allow for a more accurate distinction between EOS and AIS.

AIS, or late-onset idiopathic scoliosis, usually does not exceed $80^{\circ}$ after cessation of growth when left untreated [5] and is therefore almost never responsible for increased mortality [51]. This is why practitioners must distinguish between EOS and AIS in patients, as each type has a very different prognosis $[1,10]$.

\section{Implications of treatment}

There is a growing body of evidence concluding that surgery is rarely necessary for AIS [24-26,52] and that it is usually done for cosmetic and psychological purposes. Based on the current literature, Westrick and Ward [25] concluded that there is no medical necessity for surgery for AIS; this conclusion was recently confirmed by the results of a Cochrane review [26].

Surgery for AIS carries risks and long-term consequences. Low back pain $[53,54]$ and potential disc degen- 
eration [55] may increase over time after spinal fusion surgery [54]. For these reasons, spinal fusion is not proven to prevent low back pain in patients with AIS. In addition, a recent study shows that spinal fusion surgery does not improve the health-related quality of life of patients with AIS [56].

According to the current literature, to provide a balanced view regarding risks and benefits of surgical treatment in patients with AIS, we have to take into account that: (1) no high-quality evidence is available to support the claim that spinal fusion surgery may improve signs and symptoms of AIS $[22,24-26,52,57,58]$ and (2) surgery carries many risks and other, yet unknown long-term consequences [22,53,59-61].

Therefore, considering that there is no evidence that the signs and symptoms of scoliosis can be improved in the long-term, no medical indication for spinal fusion surgery in AIS can be derived [25]. Considering that AIS is at present considered to be a relatively benign condition $[1,5,13,17-19,30,48]$, the adverse long-term consequences of surgery may be more harmful than the adverse effects of the disease itself [22,53,59-61].

For patients with EOS, recent surgical techniques may drastically improve the deformity and enhance the quality of life. Despite this, it should be noted that there are no long-term results available for these procedures, and it is not clear whether the signs and symptoms of scoliosis, i.e., severe pain, cardiopulmonary compromise, lack of social participation, and early death can be prevented in the long-term in EOS cases [57]. One study with a follow-up of up to twenty years after the first double-rod instrumentation showed a significant rate of re-operation [53].

EOS warrants high-quality conservative treatment to reduce the rate of surgery [62-64]. Particularly for brace treatment, the quality is determined by the in-brace correction and comfort, as we know that in-brace correction and the time for which a brace is worn each day determine the outcome [65]. For AIS, the natural history research shows that for patients with curves below $30^{\circ}$ who are at Risser 3 or more, observation alone may be justified. At that point, significant consequences for the patient are less likely [15]. However, for adolescents with curves exceeding $30^{\circ}$, i.e., up to Risser 4 , conservative measures should be implemented to attempt to reduce the curve so that the chance of progression during adulthood is lessened [1].

Brace overtreatment has been recently criticized $[66,67]$ and should be avoided, according to indication guidelines for AIS [15] determined by the Lonstein and Carlson progression factor [11]. Patient history should contain information about the onset of the deformity to permit appropriate prognostication and treatment plan [15]. This is paramount as AIS has been identified as a benign deformity $[1,5]$, while the rarer EOS condition may instead have severe consequences if left untreated [10,21].

According to the literature referred for this review, there is only one indication for spinal fusion surgery in patients with AIS; it should be considered only in cases with severely decompensated curvatures exceeding $45^{\circ}$ and reduced quality of life as a result of social isolation. Thus, when AIS patients avoid swimming or socializing with friends because of the deformity, surgery should be considered. In this case, the patients should be informed that the deformity may return in the long-term and to some extent after surgery [22]. The decision to have surgery, however, has to be made by the patient and not by the surgeon. This evidence-based rationale is employed and promoted by Ward et al. [56].

The materials found in this review present some limitations.

We have speculated that the increased mortality in young patients with idiopathic scoliosis, as reported by Nilsonne and Lundgren [21], is due to the inclusion of EOS. Other confounding factors, such as excessive radiation exposure, have not been considered when explaining early deaths occurring in this patient population sample [21]. Notably, it is possible that some patients reported in the paper by Nilsonne and Lundgren [21] may have died due to conditions unrelated to scoliosis. Finally, the inclusion criteria in the referred study were not clear [21], and thus, congenital scoliosis and syndromic scoliosis may have been included as well.

Although there are several papers addressing the topic $[1,5,13,17-19,30,48]$, only a few studies from the same series (Iowa studies) include AIS follow-up periods exceeding 20 years $[5,17,19]$.

\section{Conclusions}

Early studies on the long-term effects of idiopathic scoliosis may be disregarded since they likely contain a percentage of patients with early-onset scoliosis, which causes the results to be skewed with regard to potentially fatal consequences.

More recent studies on the long-term effects of AIS do 
not include patients with EOS, thus leading to the conclusion that AIS is a relatively benign disorder.

It is important to distinguish between EOS and AIS to determine an appropriate treatment plan based on a more accurate age of onset and prognosis.

\section{Conflict of Interest}

HR Weiss is receiving financial support for attending symposia and receives royalties from Koob $\mathrm{GmbH} \& \mathrm{Co}$ KG. The company is held by the spouse of HR Weiss.

None of the other authors report any competing interest or potential conflict of interest.

\section{References}

1. Asher MA, Burton DC. Adolescent idiopathic scoliosis: natural history and long term treatment effects. Scoliosis 2006;1:2.

2. Goldberg CJ, Moore DP, Fogarty EE, Dowling FE. Adolescent idiopathic scoliosis: natural history and prognosis. Stud Health Technol Inform 2002;91:5963.

3. Lonstein JE. Patient evaluation. In: Lonstein JE, Winter RB, Bradford DS, Ogilvie JW, editor. Moe's textbook of scoliosis and other spinal deformities. 3rd ed. Philadelphia: W.B. Saunders; 1995. p.45-86.

4. Weinstein SL. Natural history. Spine (Phila Pa 1976) 1999;24:2592-600.

5. Weinstein SL, Dolan LA, Spratt KF, Peterson KK, Spoonamore MJ, Ponseti IV. Health and function of patients with untreated idiopathic scoliosis: a 50-year natural history study. JAMA 2003;289:559-67.

6. Weiss HR, Lehnert-Schroth C, Moramarco M. Schroth therapy: advancements in conservative scoliosis treatment. Saarbruecken: Lambert Academic Publishing LAP; 2015.

7. Winter RB. Classification and terminology. In: Lonstein JE, Winter RB, Bradford DS, Ogilvie JW, editors. Moe's textbook of scoliosis and other spinal deformities. 3rd ed. Philadelphia: W.B. Saunders; 1995. p.3943.

8. Lonstein JE. Adolescent idiopathic scoliosis. Lancet 1994;344:1407-12.

9. Weinstein SL. Adolescent idiopathic scoliosis: prevalence and natural history. Instr Course Lect 1989;38: 115-28.
10. Lonstein J. Idiopathic scoliosis. In: Lonstein JE, Winter RB, Bradford DS, Ogilvie JW, editors. Moe's textbook of scoliosis and other spinal deformities. 3rd ed. Philadelphia: W.B. Saunders; 1995. p.219-56.

11. Lonstein JE, Carlson JM. The prediction of curve progression in untreated idiopathic scoliosis during growth. J Bone Joint Surg Am 1984;66:1061-71.

12. Weinstein SL, Ponseti IV. Curve progression in idiopathic scoliosis. J Bone Joint Surg Am 1983;65:44755.

13. Weinstein SL. Idiopathic scoliosis: natural history. Spine (Phila Pa 1976) 1986;11:780-3.

14. Weinstein SL, Dolan LA, Cheng JC, Danielsson A, Morcuende JA. Adolescent idiopathic scoliosis. Lancet 2008;371:1527-37.

15. Weiss HR, Negrini S, Rigo M, et al. Indications for conservative management of scoliosis (guidelines). Scoliosis 2006;1:5.

16. Weiss HR, Working Group (Santos-Leal, Schneider, Werkmann, Wirth). Leitlinien der orthopädischen rehabilitation. Spezielles Rehabilitationskonzept Wirbelsäulendeformitäten [Internet]. AWMF Online; 2012 [cited 2016 Mar 31]. Available from: http:// www.awmf.org/awmf-online-das-portal-der-wissenschaftlichen-medizin/awmf-aktuell.html2012.

17. Collis DK, Ponseti IV. Long-term follow-up of patients with idiopathic scoliosis not treated surgically. J Bone Joint Surg Am 1969;51:425-45.

18. Danielsson AJ. Natural history of adolescent idiopathic scoliosis: a tool for guidance in decision of surgery of curves above 50 degrees. J Child Orthop 2013;7:37-41.

19. Weinstein SL, Zavala DC, Ponseti IV. Idiopathic scoliosis: long-term follow-up and prognosis in untreated patients. J Bone Joint Surg Am 1981;63:70212.

20. Halm H. OP-Indikationen bei Skoliose. Berlin: Deutscher Kongress für Orthopädie und Unfallschirurgie (DKOU); 2015.

21. Nilsonne U, Lundgren KD. Long-term prognosis in idiopathic scoliosis. Acta Orthop Scand 1968;39:45665.

22. Hawes M. Impact of spine surgery on signs and symptoms of spinal deformity. Pediatr Rehabil 2006; 9:318-39.

23. Weiss HR. Adolescent idiopathic scoliosis (AIS): an indication for surgery? A systematic review of the 
literature. Disabil Rehabil 2008;30:799-807.

24. Weiss HR, Goodall D. The treatment of adolescent idiopathic scoliosis (AIS) according to present evidence. A systematic review. Eur J Phys Rehabil Med 2008;44:177-93.

25. Westrick ER, Ward WT. Adolescent idiopathic scoliosis: 5-year to 20-year evidence-based surgical results. J Pediatr Orthop 2011;31(1 Suppl):S61-8.

26. Bettany-Saltikov J, Weiss HR, Chockalingam N, et al. Surgical versus non-surgical interventions in people with adolescent idiopathic scoliosis. Cochrane Database Syst Rev 2015;(4):CD010663.

27. Tan KJ, Moe MM, Vaithinathan R, Wong HK. Curve progression in idiopathic scoliosis: follow-up study to skeletal maturity. Spine (Phila Pa 1976) 2009;34:697700.

28. Goldberg CJ, Moore DP, Fogarty EE, Dowling FE. The natural history of early onset scoliosis. Stud Health Technol Inform 2002;91:68-70.

29. von Strempel A, Schloz M, Diedrich O. Long-term follow-up in patients with idiopathic scoliosis. Z Orthop Ihre Grenzgeb 1995;133:256-69.

30. Ascani E, Bartolozzi P, Logroscino CA, et al. Natural history of untreated idiopathic scoliosis after skeletal maturity. Spine (Phila Pa 1976) 1986;11:784-9.

31. Wong HK, Tan KJ. The natural history of adolescent idiopathic scoliosis. Indian J Orthop 2010;44:9-13.

32. Goldberg CJ, Moore DP, Fogarty EE, Dowling FE. Scoliosis: a review. Pediatr Surg Int 2008;24:129-44.

33. Winiarski A, Zarzycki D, Koniarski A, Kalicinski M. The natural history of idiopathic scoliosis. Ortop Traumatol Rehabil 2005;7:1-7.

34. Parent S, Newton PO, Wenger DR. Adolescent idiopathic scoliosis: etiology, anatomy, natural history, and bracing. Instr Course Lect 2005;54:529-36.

35. Bollini G, Jouve JL, Lecoq C, Garron E. Idiopathic scoliosis: evaluation of the results. Bull Acad Natl Med 1999;183:757-67.

36. Guillaumat M. Natural history of scoliosis from childhood to old age. Bull Acad Natl Med 1999;183: 705-18.

37. Roach JW. Adolescent idiopathic scoliosis. Orthop Clin North Am 1999;30:353-65.

38. Miller NH. Cause and natural history of adolescent idiopathic scoliosis. Orthop Clin North Am 1999;30: 343-52.

39. Cordover AM, Betz RR, Clements DH, Bosacco SJ.
Natural history of adolescent thoracolumbar and lumbar idiopathic scoliosis into adulthood. J Spinal Disord 1997;10:193-6.

40. Montgomery F, Willner S. The natural history of idiopathic scoliosis. Incidence of treatment in 15 cohorts of children born between 1963 and 1977. Spine (Phila Pa 1976) 1997;22:772-4.

41. Pecina M, Dakovic M, Bojanic I. The natural history of mild idiopathic scoliosis. Acta Med Croatica 1992; 46:75-8.

42. Gunnoe BA. Adolescent idiopathic scoliosis. Orthop Rev 1990;19:35-43.

43. Bunnell WP. The natural history of idiopathic scoliosis. Clin Orthop Relat Res 1988;(229):20-5.

44. Edgar MA. The natural history of unfused scoliosis. Orthopedics 1987;10:931-9.

45. Rogala EJ, Drummond DS, Gurr J. Scoliosis: incidence and natural history: a prospective epidemiological study. J Bone Joint Surg Am 1978;60:173-6.

46. Lloyd-Roberts GC, Pilcher MF. Structural idiopathic scoliosis in infancy: a study of the natural history of 100 patients. J Bone Joint Surg Br 1965;47:520-3.

47. Scott JC, Morgan TH. The natural history and prognosis of infantile idiopathic scoliosis. J Bone Joint Surg Br 1955;37:400-13.

48. Nachemson A. A long term follow-up study of nontreated scoliosis. Acta Orthop Scand 1968;39:466-76.

49. James JI. Idiopathic scoliosis; the prognosis, diagnosis, and operative indications related to curve patterns and the age at onset. J Bone Joint Surg Br 1954; 36:36-49.

50. Weiss HR. The method of Katharina Schroth: history, principles and current development. Scoliosis 2011; 6:17.

51. Pehrsson K, Larsson S, Oden A, Nachemson A. Long-term follow-up of patients with untreated scoliosis: a study of mortality, causes of death, and symptoms. Spine (Phila Pa 1976) 1992;17:1091-6.

52. Weiss HR. Is there a body of evidence for the treatment of patients with adolescent idiopathic scoliosis (AIS)? Scoliosis 2007;2:19.

53. Mueller FJ, Gluch H. Cotrel-dubousset instrumentation for the correction of adolescent idiopathic scoliosis: long-term results with an unexpected high revision rate. Scoliosis 2012;7:13.

54. Upasani VV, Caltoum C, Petcharaporn M, et al. Adolescent idiopathic scoliosis patients report increased 
pain at five years compared with two years after surgical treatment. Spine (Phila Pa 1976) 2008;33:110712.

55. Nohara A, Kawakami N, Seki K, et al. The effects of spinal fusion on lumbar disc degeneration in patients with adolescent idiopathic scoliosis: a minimum 10year follow-up. Spine Deform 2015;3:462-8.

56. Ward WT, Friel N, Kenkre TS, Brooks MM. SRS $22 \mathrm{r}$ scores in non-operated AIS patients with curves $\geq 40^{\circ}$. In: Proceedings of the 50th Annual Meeting Minneapolis; Sep 30-Oct 3 2015; Minneapolis MN, USA.

57. Weiss HR, Turnbull D, Tournavitis N, Borysov M. Treatment of scoliosis-evidence and management: review of the literature. Middle East J Rehabil Health 2016;3:e35377.

58. Hawes MC, O'Brien JP. A century of spine surgery: what can patients expect? Disabil Rehabil 2008;30: 808-17.

59. Weiss HR, Moramarco M, Moramarco K. Risks and long-term complications of adolescent idiopathic scoliosis surgery versus non-surgical and natural history outcomes. Hard Tissue 2013;2:27.

60. Weiss HR, Goodall D. Rate of complications in scoliosis surgery: a systematic review of the Pub Med literature. Scoliosis 2008;3:9.
61. Weiss HR, Moramarco M. Indication for surgical treatment in patients with adolescent idiopathic scoliosis: a critical appraisal. Patient Saf Surg 2013;7:17.

62. Weinstein SL, Dolan LA, Wright JG, Dobbs MB. Effects of bracing in adolescents with idiopathic scoliosis. N Engl J Med 2013;369:1512-21.

63. Weiss HR, Moramarco M. Remodelling of trunk and backshape deformities in patients with scoliosis using standardized asymmetric computer-aided design/ computer-aided manufacturing braces. Hard Tissue 2013;2:14.

64. Weiss HR, Kleban A. Development of CAD/CAM based brace models for the treatment of patients with scoliosis-classification based approach versus finite element modelling. Asian Spine J 2015;9:661-7.

65. Ng SY, Borysov M, Moramarco M, Nan XF, Weiss HR. Bracing scoliosis: state of the art (mni-review). Curr Pediatr Rev 2016;12:36-42.

66. Castelein RM. The benefit of braces in adolescent idiopathic scoliosis. Ned Tijdschr Geneeskd 2014; 158:A7246.

67. Sanders JO, Newton PO, Browne RH, Katz DE, Birch JG, Herring JA. Bracing for idiopathic scoliosis: how many patients require treatment to prevent one surgery? J Bone Joint Surg Am 2014;96:649-53. 